\title{
MODEX: \\ LABORATORY EXPERIMENT EXPLORING SEDIMENT SPREADING OF A MOUND UNDER WAVES AND CURRENTS
}

\author{
MATTHIEU DE SCHIPPER ${ }^{1}$, J. HOPKINS ${ }^{1}$, M. WENGROVE ${ }^{2}$, I.SAXONI ${ }^{1}, \mathrm{M}^{3}$. \\ KLEINHANS ${ }^{3}$, N. SENECHAL ${ }^{4}$, B.CASTELLE ${ }^{4}$, F. RIBAS ${ }^{5}$, B.G. RUESSINK ${ }^{3}$, B. \\ MURPHY $^{6}$, S. MCLELLAND
}

1. Department of Hydraulic Engineering, Faculty of Civil Engineering, Delft University of Technology, the Netherlands, M.A.deSchipper@TUDelft.nl, J.A.Hopkins@TUDelft.nl,I.Saxoni@student.TUDelft.nl

2. School of Civil \& Construction Engineering, Oregon State University, Corvallis, USA, meagan.wengrove@oregonstate.edu

3. Faculty of Geosciences, Utrecht University, the Netherlands, M.G.Kleinhans@uu.nl B.G.Ruessink@uu.nl

4. EPOC,Université de Bordeaux,Francen.senechal@epoc.u-bordeaux1.fr. b.castelle@epoc.u-bordeaux1.fr

5. Universitat Politècnica de Catalunya,Spain francesca.ribas@upc.edu

6. University of Hull, United Kingdom,B.J.Murphy@hull.ac.uk S.J.McLelland@hull.ac.uk

\begin{abstract}
The dispersal of sand from submerged mounds in the nearshore is driven by the interplay of processes such as converging and recirculating flows, changing roughness, bed slope effects and wave focusing/refraction. This morphological diffusivity is key to understanding sand bars in shallow seas, tidal inlets, estuaries, and the nearshore response to human interventions such as nourishments and dredging. Most of the work on the evolution of submerged mounds has been based on fluvial studies, focusing on flow without waves. In these cases, circular mounds tend to deform to crescentic (barchan) shapes. In contrast, observations of sandbars and berms in the nearshore subjected to waves show much more complex translation and deformation behavior. This contribution introduces the laboratory MOrphological Diffusivity Experiment (MODEX) aimed at examining morphological diffusivity under different forcing conditions. The experiment particularly addresses the linkages between small scale (local) effects (e.g. bed slope, bedforms) on the adjustment of sandy mounds.
\end{abstract}

\section{Introduction}

Morphological diffusivity, or the tendency of large morphological shapes to flatten due to feedback under flow conditions, is key to understanding the behavior of sand bars in shallow seas, tidal inlets, estuaries, and the nearshore response to human interventions such as nourishments and dredging. The diffusivity and feedback can be the result of wave angle variations alongshore, converging and recirculating flows, changing roughness, bed slope effects and wave focusing/refraction (e.g. Pelnard-Considère, 1956; Moulton et al., 2014; de 
Schipper et al., 2014; Smit, 2010; Price et al., 2014). The understanding and predicting ability of this three-dimensional behavior is currently impeded by 1) a lack of data and 2) incomplete understanding of the underlying physical processes that govern the behavior on larger scales (e.g. bed slope effects, Baar et al., 2018). As a result, the morphodynamic models used to understand natural behavior (e.g. rhythmic sand bars) show a strong dependence on the parameterization of morphodynamic diffusivity (e.g. Dubarbier et al., 2017).

The lack of data on three-dimensional morphological diffusivity originates from the difficulty of experimenting in the natural system, viz. the signal-to-noise ratio of observed diffusivity in natural situations is low. During normal conditions, bed level changes are dominated by day-to-day variation in forcing, obstructing a clear view on the overall diffusivity. Yet, this behavior is often exploited to validate numerical models. A classical test case is the Gaussian Hump test of de Vriend (1987), showing the morphological diffusivity for a bed with constant roughness in a unidirectional current (i.e. no waves). This test case is often used for model validation (e.g. Lesser et al., 2004, Cowles 2013) and replicated in the lab by Garcia-Hermosa (2008). Overall these tests reveal that circular mounds reshape into crescentic (barchan) shapes. In contrast, observations of mounds subjected to waves such as sandbars and berms in the nearshore show much more complex behavior with translation and deformation. The diffusivity under waves and currents was experimented first in Moulton et al. (2014), suggesting that bed slope may explain most of the behavior. Yet due to the complex nature of field experiments, the evolution could not be related to forcing in detail.

This contribution introduces the laboratory MOrphological Diffusivity Experiment (MODEX) aimed at examining morphological diffusivity under different types of forcing conditions. To examine three-dimensional morphological diffusivity, an experiment similar to the theoretical Gaussian Hump test case (de Vriend, 1987) was designed. The experiment particularly addresses the linkages between small scale (local) effects (e.g. bed slope, bedforms) on the adjustment of sandy mounds. Following the experiment the research is focused amongst others on 1) spreading rates, 2) prediction skill using numerical models, 3) ripple formation and 4) linking ripple scale with overall spreading. MODEX is a collaboration between Delft University of Technology, Utrecht University, Oregon State University, CNRS, Université de Bordeaux, Universitat Politècnica de Catalunya and the University of Hull and made possible through the Hydralab+ program of the E.U. Data is made available on a repository to facilitate a wide use.

This contribution describes the experiment setup, the execution of the test program and the initial results. The Hopkins et al. (2019) and Lee et al. (2019) 
contributions to this Coastal Sediments 2019 conference present more detailed results of sub-projects.

\section{Methodology}

\section{Experimental Setup}

The experiment was executed over a 7-week period at the Total Environment Simulator (TES), a flume in Hull, United Kingdom in May and June 2018. The TES has the possibility to produce waves, currents and combined flows (waves + following currents) and suited to the installation of a wide planar sand bed. The flume basin is $12 \mathrm{~m}$ in length and $6 \mathrm{~m}$ in width, with eight wave paddles located at one end and recirculating flow (Figure 1). For the experiment, the basin was filled with a $0.1 \mathrm{~m}$ thick layer of sand with a D50 of $215 \mu \mathrm{m}$. Water level was raised to a water depth of $0.4 \mathrm{~m}$ above the main bed with fresh water. To allow for waves to be dissipated, a beach-like structure was constructed on the downstream end of the flume. The slope of this beach was approximately 1:5 and the surface was covered by artificial grass to increase the roughness. The beach structure was mounted $0.2 \mathrm{~m}$ above the bed level to allow for the current to flow into the recirculation system. Additionally, the beach was perforated by $0.032 \mathrm{~m}$ holes approximately $0.08 \mathrm{~m}$ apart (centre-to-centre) to attain a surface permeability of about 10 to $15 \%$ for the flow to pass through.
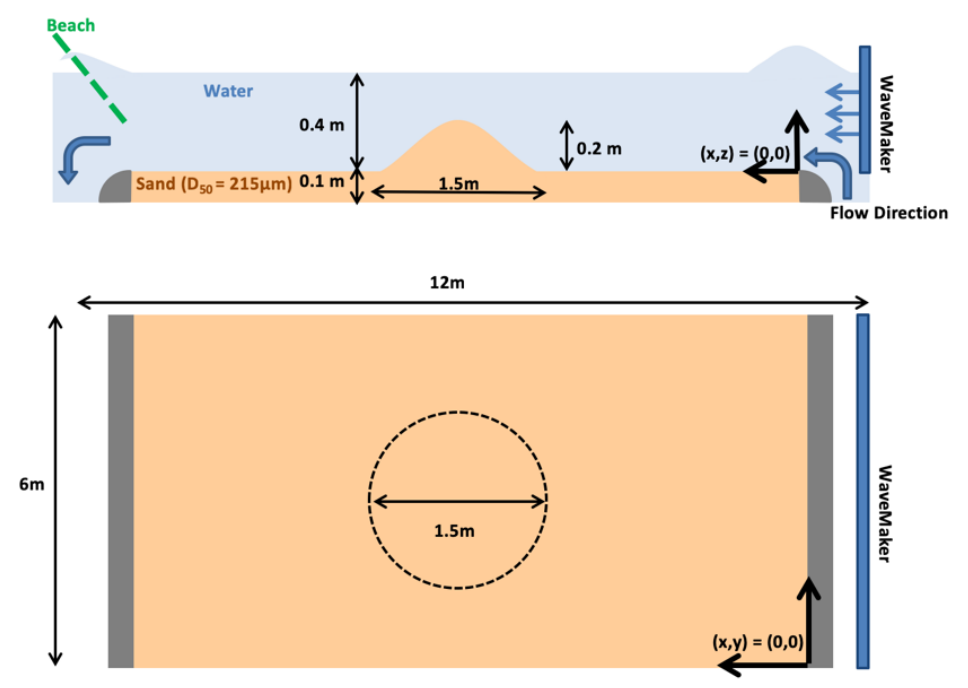

Fig. 1. Side (top) and plan view (bottom) schematic of the TES facility during MODEX (Not to scale). 
For each test a mound was constructed in the center of the flume. The dimensions of the mound are based on a gaussian with standard deviation of $0.3 \mathrm{~m}(\sim 1.5 \mathrm{~m}$ diameter) and $0.2 \mathrm{~m}$ height at its peak, resulting of a mound height to ambient water depth of 0.5 at the start. The mound was designed to be axial symmetric and constructed using a mold consisting of an outer rim and a rotating profile board around the center to obtain similar initial bed conditions prior to each test (Figure 2).
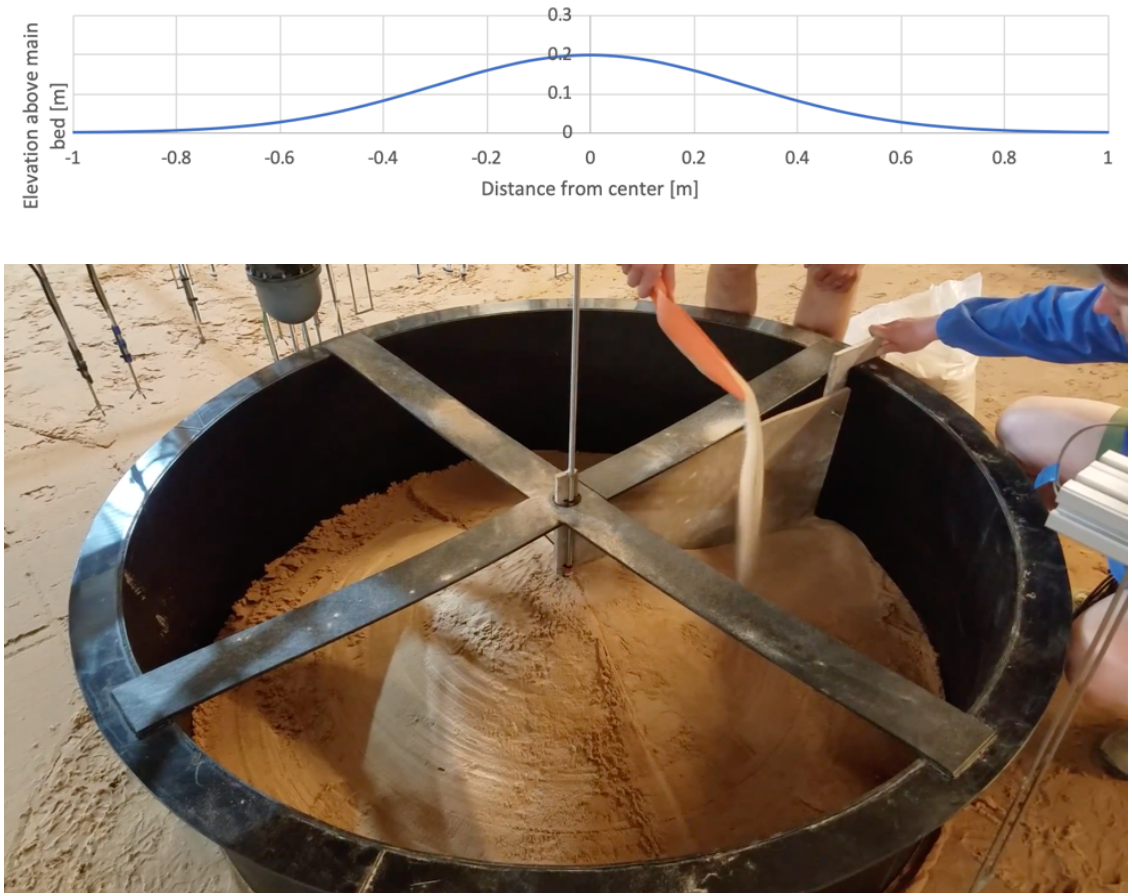

Fig. 2. Mound profile (top panel) and construction method in the flume.

After each of the nine tests, the bed of the full flume was flattened to remove ripples and recreate a similar initial condition.

\section{Experimental Program}

The various tests focus on subjecting the mound to various wave and current conditions and monitoring its morphological response (Table 1). The wave conditions were tailored to the limitations of the wavemaker and in the nonbreaking regime. The forcing conditions were chosen such that transport were mostly in the bedload regime. In combined experiments the ratio of currents and wave forcing was chosen based on estimates of shear stress, such that waves and 
currents approximately result in similar stress or that one of the two dominates (Table 1).

Table 1. Forcing conditions used during different tests of the experiment. $\Theta$ refers to the expected non-dimensional shear stress (Shields parameter) for waves $\Theta_{w}$ or currents $\Theta_{c}$ used to create a dominance of either of the two. Currents follow from the imposed flow rate divided by the wet cross-section ( 6 by $0.4 \mathrm{~m}$ ). Values are the imposed values, observed values near the centre of the mound given in bold.

\begin{tabular}{|c|c|c|c|}
\hline $\begin{array}{l}\text { Tests } \\
\text { date }\end{array}$ & $\begin{array}{l}\text { Wave forcing } \\
\text { (monochromatic) }\end{array}$ & Flow rate & $\begin{array}{l}\text { Total time } \\
\text { (intervals) }\end{array}$ \\
\hline $\begin{array}{l}\text { T1 Waves only (low) } \\
16 \& 17 \text { May } \\
\text { (day of year } 136 \& 137 \text { ) }\end{array}$ & $\begin{array}{l}\mathrm{T}=1 \mathrm{~s}, \mathrm{H}=0.11 \mathrm{~m} \\
(\mathbf{0 . 1 0} \mathbf{~ m})\end{array}$ & - & $150 \mathrm{~min}$ \\
\hline $\begin{array}{l}\text { T2 Waves only (medium) } \\
21 \& 22 \text { May }(141 \& 142)\end{array}$ & $\begin{array}{l}\mathrm{T}=1.2 \mathrm{~s}, \mathrm{H}=0.14 \mathrm{~m} \\
(\mathbf{0 . 1 2} \mathbf{~ m})\end{array}$ & - & $\begin{array}{l}90 \mathrm{~min} \\
(9 \times 10)\end{array}$ \\
\hline $\begin{array}{l}\text { T3 Waves only (high) } \\
24 \text { \& } 25 \text { May }(144 \text { \& 145) }\end{array}$ & $\begin{array}{l}\mathrm{T}=1.3 \mathrm{~s}, \mathrm{H}=0.16 \mathrm{~m} \\
(\mathbf{0 . 1 2} \mathbf{~ m})\end{array}$ & - & $\begin{array}{l}60 \mathrm{~min} \\
(9 \times 6.66)\end{array}$ \\
\hline $\begin{array}{l}\text { T4 Current only (large) } \\
30 \text { May (150) }\end{array}$ & - & $900 \mathrm{l} / \mathrm{s}, 0.38 \mathrm{~m} / \mathrm{s}$ & $\begin{array}{l}35 \min \\
(10+5 \times 5)\end{array}$ \\
\hline $\begin{array}{l}\text { T5 Current only (medium) } \\
\text { 1 June (152) }\end{array}$ & - & $7001 / \mathrm{s}, 0.29 \mathrm{~m} / \mathrm{s}$ & $\begin{array}{l}40 \min \\
(8 \times 5)\end{array}$ \\
\hline $\begin{array}{l}\text { T6 Wave+Currents (low energy) } \\
5 \text { June (156) }\end{array}$ & $\begin{array}{l}\mathrm{T}=0.85 \mathrm{~s}, \mathrm{H}=0.07 \mathrm{~m} \\
(\mathbf{0 . 0 5 5 m )}\end{array}$ & $400 \mathrm{l} / \mathrm{s}, 0.17 \mathrm{~m} / \mathrm{s}$ & $\begin{array}{l}125 \mathrm{~min} \\
(5+5+10+15 \\
+30+30+30)\end{array}$ \\
\hline $\begin{array}{l}\text { T7 Wave }+ \text { Currents }\left(\Theta_{w} \approx \Theta_{c}\right) \\
7 \text { June }(158)\end{array}$ & $\begin{array}{l}\mathrm{T}=1.2 \mathrm{~s}, \mathrm{H}=0.14 \mathrm{~m} \\
(\mathbf{0 . 1 0} \mathbf{~ m})\end{array}$ & $5001 / \mathrm{s}, 0.21 \mathrm{~m} / \mathrm{s}$ & $\begin{array}{l}45 \min \\
(9 \times 5)\end{array}$ \\
\hline $\begin{array}{l}\text { T8 Wave }+ \text { Currents }\left(\Theta_{w}<\Theta_{c}\right) \\
11 \text { June }(162)\end{array}$ & $\mathrm{T}=1.0 \mathrm{~s}, \mathrm{H}=0.11 \mathrm{~m}$ & $580 \mathrm{l} / \mathrm{s}, 0.24 \mathrm{~m} / \mathrm{s}$ & $\begin{array}{l}47 \min \\
(2+9 \times 5)\end{array}$ \\
\hline $\begin{array}{l}\text { T9 Wave }+ \text { Currents }\left(\boldsymbol{\Theta}_{w}>\boldsymbol{\Theta}_{c}\right) \\
\text { 13 June }(164)\end{array}$ & $\mathrm{T}=1.3 \mathrm{~s}, \mathrm{H}=0.16 \mathrm{~m}$ & $420 \mathrm{l} / \mathrm{s}, 0.18 \mathrm{~m} / \mathrm{s}$ & $\begin{array}{l}45 \mathrm{~min} \\
(9 \times 5)\end{array}$ \\
\hline
\end{tabular}




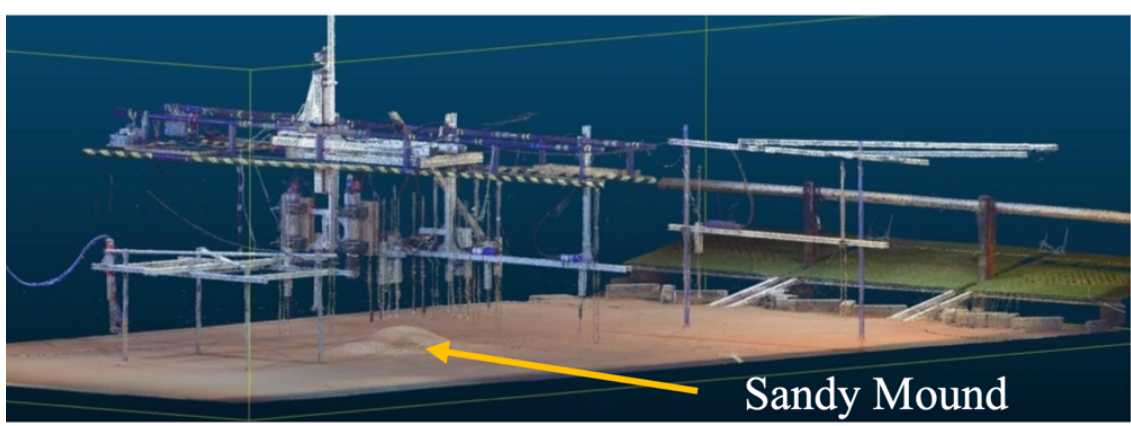

Fig. 3. Laserscan point-cloud of the sandy bed with the mound prior to a test. Beach is visible at the right side in green. Overhead gantry (visible by the yellow and black hazard tape) was used to mount instruments off the bed.

\section{Observation Techniques}

A wide range of measurement devices was employed above and around the mound to capture the bed response and the concurrent forcing during the experiment (Figure 3 and Figure 4).

- Bed level measurements were taken using laser scanning, rotary pencil beam sonars and ultrasonic bed altimeters to capture the deformation and translation of the mounds in detail.

Laserscanning: A FARO Focus X330 scanner was used before and after each test when the flume was drained. It was programmed at a resolution of $3 \mathrm{~mm}$ at $10 \mathrm{~m}$ distance (175 million points per scan) and set up at six stations on the edges of the sandy bed to avoid objects being in the shadow of instruments. The six scans were then stitched together in the FARO SCENE software using five permanent targets installed in the TES. The reported registration errors of the combined 3D point-cloud on these targets are about $2 \mathrm{~mm}$. With the CloudCompare software the $3 \mathrm{D}$ point-clouds were cut manually to contain the sandy bed only and then gridded to a rectangular grid with $5 \mathrm{~mm}$ resolution in the horizontal.

Rotary pencil beam sonars: Two Marine Electronics 3D Sand Ripple Profiling Logging Sonar (RPS) devices were used to map the bed while the flume was filled with water. The RPS devices contain a $1.0 \mathrm{MHz}$ narrow beam sonar that rotates around its zenith angle to create a swath, followed by rotating in the planform. This resulted in a circular bed level image with a diameter of about $1 \mathrm{~m}$. RPS devices were mounted on a moving traverse and lowered into the water between runs for scans. The backscatter data from the instruments was post-processed following Wengrove et al (2017). More on the RPS results can be found in Hopkins et al. 2019. 
Ultrasonic bed altimeters: 12 Seatek $2 \mathrm{MHz}$ ultrasonic altimeters were used to obtain local bed information while the flume was filled with water (also during flow and waves). These altimeters with small transducer diameter $(1 \mathrm{~cm})$ and narrow beam width (1.8 degrees), effectively provide a point measurement of bed elevation on an intra bedform scale. Sampling frequency was equal to $1 \mathrm{~Hz}$ (based on three pings per sample).

- Hydrodynamics were measured using wave gauges, Acoustic Doppler Velocimeter (ADV) point measurement devices and near-bed ADV profiling devices.

Wave gauges: surface elevations were recorded at seven locations using HR Wallingford resistance wave gauges. The wave gauges were of the twin rod type and require calibration with changing water temperature and salinity. Therefore, daily calibration of wave gauges was done while filling and lowering the still water level of the flume. Sampling frequency was equal to $29 \mathrm{~Hz}$.

ADV: Six Nortek ADVs were used to obtain mid-depth values of flow and wave orbital motion. Sampling frequency of the ADVs was equal to $25 \mathrm{~Hz}$.

Profiling ADVs: To obtain high detail velocity profiles of near bed velocities, four Nortek Vectrino profilers were installed along the centerline of the mound. These devices provide a $3.5 \mathrm{~cm}$ profile of velocities. By synchronizing the devices in pairs they were able to map velocity structures larger than the individual sampling ranges. Sampling frequency was equal to $50 \mathrm{~Hz}$. Additionally the Vectrino devices provide estimates of the bed level underneath the transducer head. During the tests the transducers were positioned $2-8 \mathrm{~cm}$ (varying between different tests) above the bed and lowered (or raised) as the bed eroded (accreted).

- Sediment concentration.

To obtain estimates of sediment concentrations an acoustic backscatter (ABS) device was mounted upstream of the mound. The AQUASCAT 1000R device was used with 1, 2, 3 and $5 \mathrm{MHz}$ transducers. Sampling frequency was equal to $128 \mathrm{~Hz}$.

- Additional imagery data

Four GoPro cameras were used for additional data. Three GoPro Hero 4 devices were mounted overhead to provide an overview of the water surface $(1 / 30 \mathrm{~Hz})$. An additional GoPro Hero6 camera was used for subaqueous imagery. This Hero6 
camera was mounted perpendicular to the mound to observe ripple formation at 5 second interval while the forcing acted on the mound.

Canon EOS 600 DSLR and smartphone camera images were also used for documenting the bed ripples and the experiment as a whole.
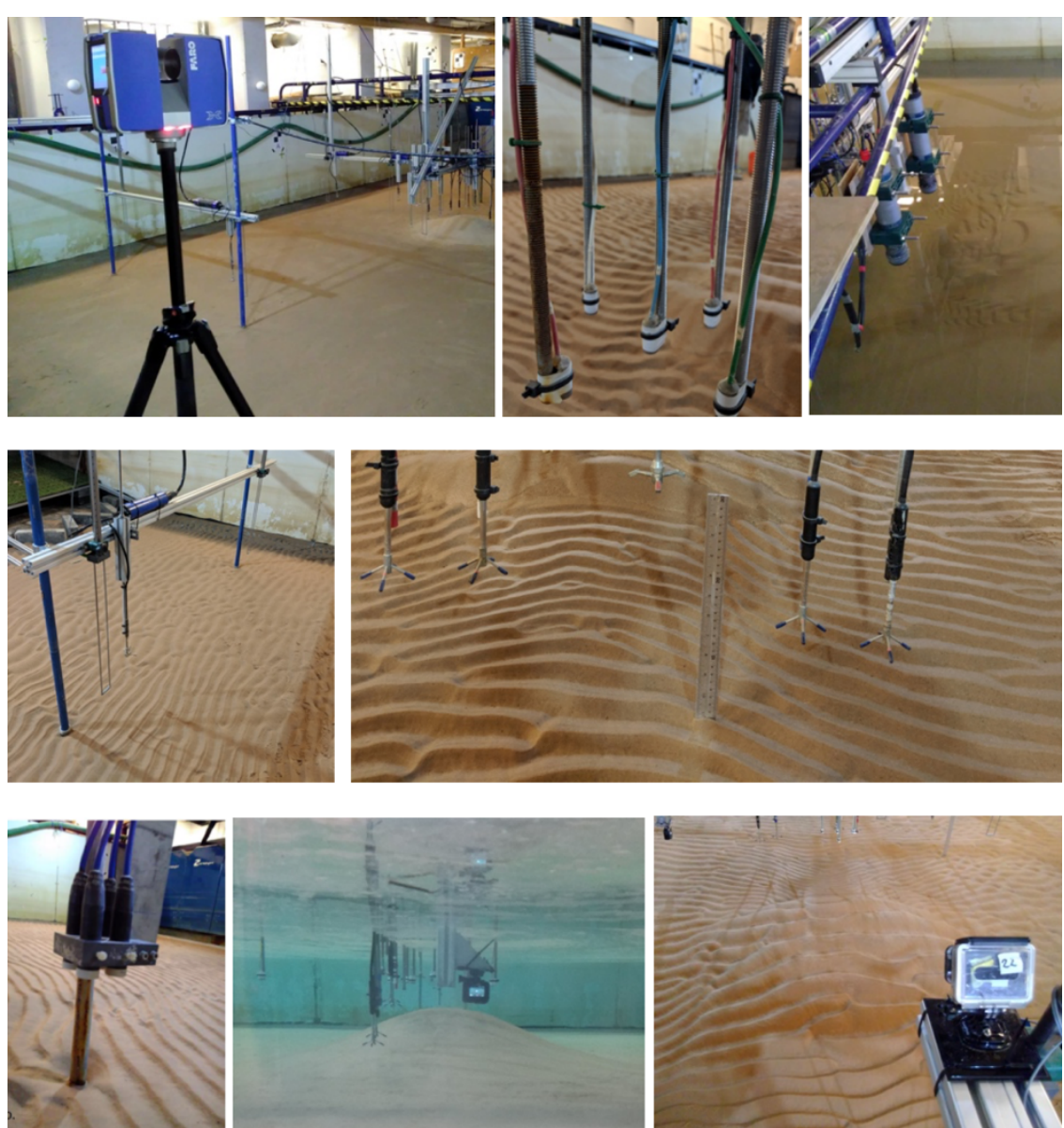

Fig. 4. Instruments used during MODEX (from left to right). Top row: Laser scanner, Ultrasonic altimeters and the two RPS scanners. Middle row: Wave rod and ADV, four near bed profiling Vectrinos. Bottom row: ABS transducers, submerged GoPro camera and overhead GoPro camera.

Most instruments were mounted off a gantry spanning across the flume, such that the bed was not disturbed. For observations of hydrodynamics before the mound a separate frame was installed with a wave gauge, ADV and the ABS. Near the 
beach a second overhead frame was used to mount a wave gauge and an ADV (Figure 3 and 5).

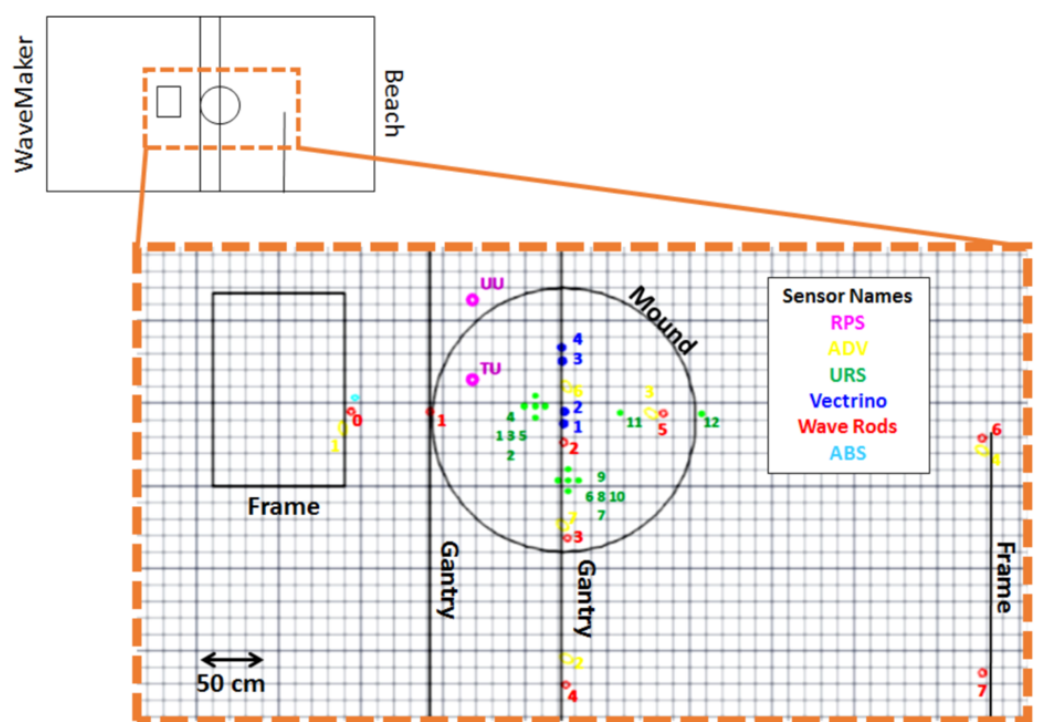

Fig. 5. Top view schematic with detail of instrument positions. Note that the RPS devices were located on a traverse and were moved laterally to map the full extent of the mound. Note that wave rod \#7 was removed from the experiment prior to test $\mathrm{T} 1$.

A test consists of six to ten runs (i.e. bursts) of forcing. During these runs the flow, waves or both were activated and the hydrodynamics and altimeters were recording. After each run the RPS devices were lowered into the water column to obtain a measurement of bed level. The length of the runs varies between 5 to 30 minutes depending on the rate at which the mound lowers. Occasionally the final runs of a test were longer to provide the bed more time to evolve. Once the mound was approximately at half its height the tests were ended (Figure 6).

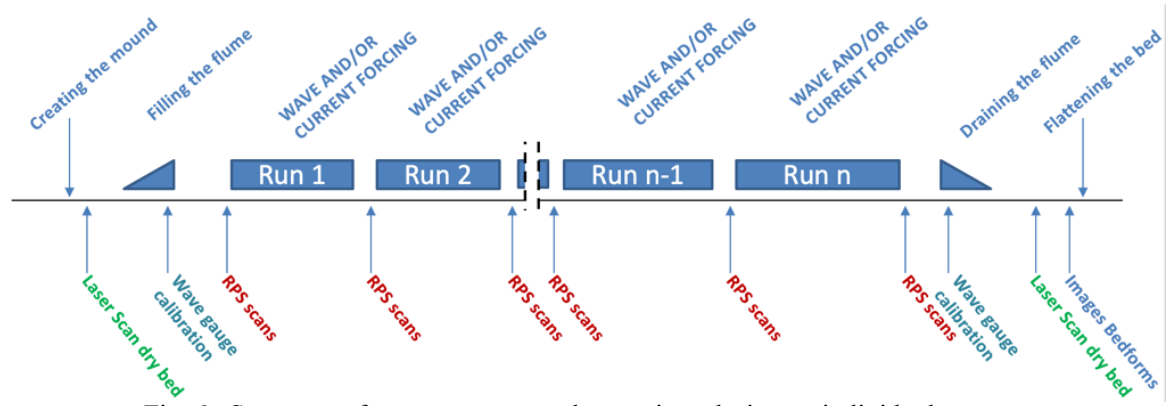

Fig. 6. Sequence of measurements and operations during an individual test. 


\section{Preliminary results}

Findings based on the experiment will be discussed at the conference, Hopkins et al. (2019) and Lee et al. (2019) contributions and subsequent publications. General observations are given here.

\section{Reproducibility}

Crucial in comparing various tests in the experiment is a near similar initial bed. This is investigated using the pre-test laserscans. A profile comparison across the flume shows the initial mounds for all tests. Standard deviations between initial bathymetries $\left(\left|\mathrm{Zb}, \mathrm{i}^{-} \mathrm{Zb}, \mathrm{j}\right|\right.$, with $\mathrm{i}$ and $\mathrm{j}_{\mathrm{j}}$ indicating different tests) are on average $0.0040 \mathrm{~m}$ (and maximum $0.0066 \mathrm{~m}$ ). These differences are likely to be caused by a slight lateral shift of the mound position rather than differences in the shape itself (Figure 7)

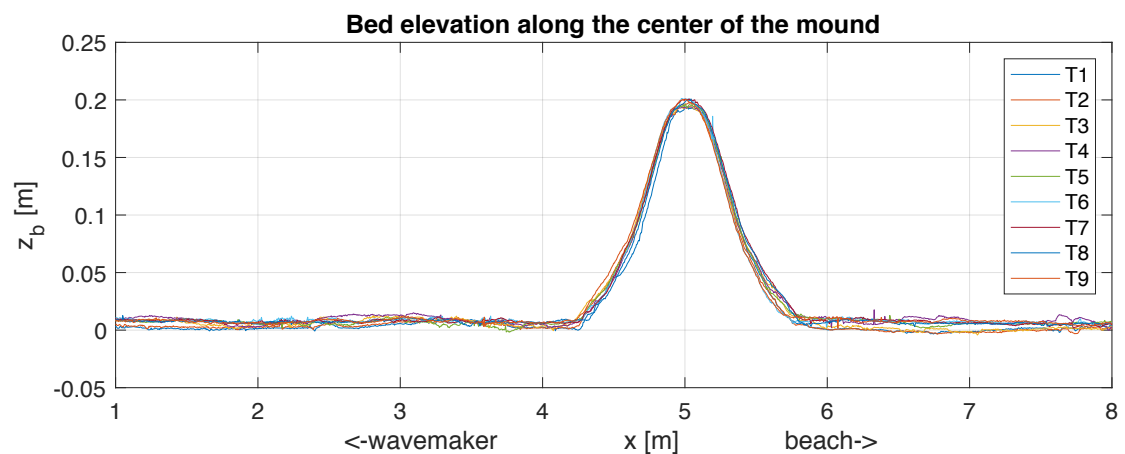

Fig. 7. Differences between initial bed levels between individual tests. Along flume profile across the pre-test laser scans. Colors indicate the profiles prior to different tests.

\section{Spreading}

The overall behavior of the mound varies based on the forcing. Wave-only tests displayed a nearly invariant center of the mound, with a spreading to all sides. To assess the spreading, Gaussian fits are made to the pre- and post-test bed levels:

$$
z_{b}(x, y, t)=-H(t) \exp \left[-\left(\frac{x^{2}}{2 \sigma_{x}^{2}(t)}+\frac{y^{2}}{2 \sigma_{y}^{2}(t)}\right)\right.
$$


where $z_{b}$ is the bed level (m); $H(t)$ the height of the mound (m); $\sigma_{x}$ and $\sigma_{y}$ are the width of the mound in the direction of wave propagation and perpendicular to the wave propagation $(\mathrm{m})$. Using a least-squares fitting procedure the best fitting Gaussian can then be found for each of the bed level scans.

For the wave only tests the best fit statistics of the mounds are displayed in Table 2. Fits to the pre-test mounds all have a height of around $0.19 \mathrm{~m}$ and a width of around $0.30 \mathrm{~m}$, sufficiently matching the desired shape. The post-test fits show the relation between forcing and increase in widths of the mounds. The largest dispersion of sediment is found for the most energetic wave conditions in Test 3 . Current-only tests show more resemblance to the formation of barchan dunes, as reported by Garcia-Hermosa (2008). In these current-only tests the center of mass of the mound is moved down-current and an asymmetric profile formed with a steep lee side.

Table 2. Fitting results for the mounds in the laser scans prior and post the wave-only tests. Amp indicates the amplitude of the mound

\begin{tabular}{lllll} 
Test & Time & Amp & $\sigma_{x}$ & $\sigma_{y}$ \\
\hline T1 & Before & $0.191 \mathrm{~m}$ & $0.296 \mathrm{~m}$ & $0.319 \mathrm{~m}$ \\
& After & $0.148 \mathrm{~m}$ & $0.342 \mathrm{~m}$ & $0.390 \mathrm{~m}$ \\
$\mathrm{~T} 2$ & Before & $0.193 \mathrm{~m}$ & $0.297 \mathrm{~m}$ & $0.307 \mathrm{~m}$ \\
& After & $0.117 \mathrm{~m}$ & $0.375 \mathrm{~m}$ & $0.413 \mathrm{~m}$ \\
$\mathrm{~T} 3$ & Before & $0.188 \mathrm{~m}$ & $0.316 \mathrm{~m}$ & $0.325 \mathrm{~m}$ \\
& After & $0.118 \mathrm{~m}$ & $0.406 \mathrm{~m}$ & $0.446 \mathrm{~m}$
\end{tabular}

\section{Bedforms}

A range of bedforms were formed from an initially smooth topography during each of the tests. Depending on the forcing type, ripples were more straightcrested or linguoid-like. The various ripple patterns visible after the test show changing orientation and sizes, indicative of variations in the larger scale flow (Figure 8). 


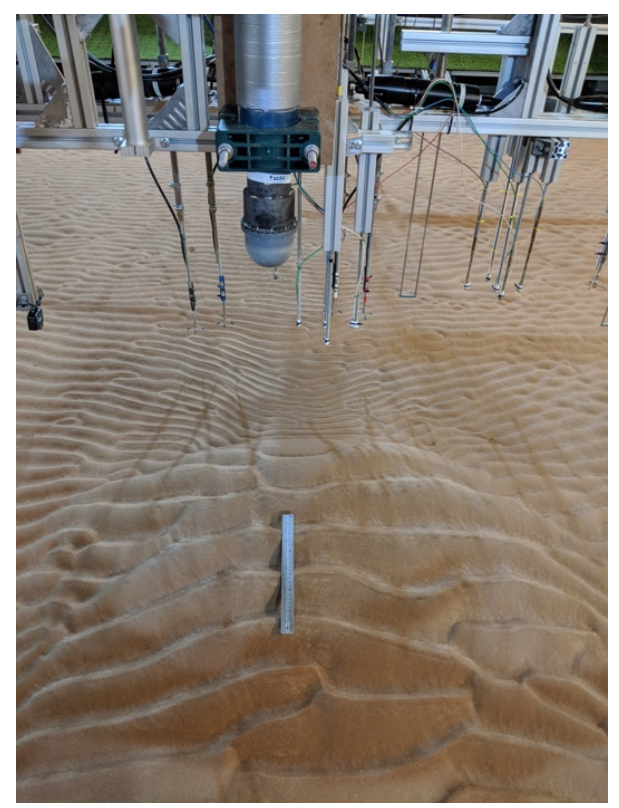

Fig. 8. Ripple patterns observed after Test 8 with waves and currents. Image facing the beach with a $30 \mathrm{~cm}$ ruler on the mound remains for scale.

\section{Concluding remarks}

A 7-week laboratory experiment to examine morphological diffusivity, MODEX, was executed in May and June of 2018. The experiment was done in the Total Environment Simulator of the University of Hull as a collaboration of Delft University of Technology, Utrecht University, Oregon State University, CNRS, Université de Bordeaux, Universitat Politècnica de Catalunya and the University of Hull. The laboratory MORphological Diffusivity Experiment (MODEX) provided experimental data of the spreading of sand under nine different forcing conditions starting from identical Gaussian mounds. The response and the forcing were recorded using a wide suite of instruments, such that the linkages between small scale (local) effects (e.g. bed slope, bedforms) and the overall dispersal of sandy mounds can be investigated.

\section{Acknowledgements}

The MODEX project was supported by the European Community's Seventh Framework Programme through the grant to the budget of the Integrated Infrastructure Initiative Hydralab+. The experiment would not have been possible 
without the nearly unlimited dedication, expertise and flexibility of the Total Environment Simulator staff, Hannah Williams and Laura Jordan. The scientific team also consisted of Anne Baar (Utrecht University), and Seok-Bong Lee (Oregon State University) WHO worked meticulously and enthusiastic to collect the data. Matthieu de Schipper is financed by NWO Domain Applied and Engineering Sciences under project code 15058.

\section{References}

Baar, A. W., de Smit, J., Uijttewaal, W. S., \& Kleinhans, M. G. (2018). Sediment transport of fine sand to fine gravel on transverse bed slopes in rotating annular flume experiments. Water Resources Research, 54(1), 19-45.

Cowles, G. W. (2013). A block-structured adaptive mesh refinement solver for morphodynamic modeling. Journal of Coastal Research, 29(3), 727-735.

Dubarbier, B., Castelle, B., Ruessink, G., \& Marieu, V. (2017). Mechanisms controlling the complete accretionary beach state sequence. Geophysical Research Letters, 44(11), 5645-5654.

García-Hermosa, M. I. (2008). Morphodynamics of sand mounds in shallow flows (Doctoral dissertation, University of Oxford).

Hopkins, J., de Schipper, M.A., Wengrove, M. et al. (2019). Observations and numerical model results of morphodynamic feedback owing to wave-current interaction, this conference.

Lee S.B., Wengrove, M., Hopkins, J., Saxoni, I. \& de Schipper M.A. (2019). Wave driven sand ripple formation and evolution on a mound, this conference.

Lesser, G. R., Roelvink, J. V., Van Kester, J. A. T. M., \& Stelling, G. S. (2004). Development and validation of a three-dimensional morphological model. Coastal Engineering, 51(8-9), 883-915.

Moulton, M., Elgar, S., \& Raubenheimer, B. (2014). A surfzone morphological diffusivity estimated from the evolution of excavated holes. Geophysical Research Letters, 41(13), 4628-4636. 
Pelnard-Considere, R. (1956). Essai de theorie de l'evolution des formes de rivage en plages de sable et de galets. Les Energies de la Mer: Compte Rendu Des Quatriemes Journees de L'hydraulique, Paris 13, 14 and 15 Juin 1956;

Price, T. D., Ruessink, B. G., \& Castelle, B. (2014). Morphological coupling in multiple sandbar systems-a review. Earth Surface Dynamics, 2(1), 309-321.

de Schipper, M. A., Reniers, A. J., Ranasinghe, R., \& Stive, M. J. (2014). The influence of sea state on formation speed of alongshore variability in surf zone sand bars. Coastal Engineering, 91, 45-59.

Smit, M. W. J. (2010). Formation and evolution of nearshore sandbars. (Doctoral dissertation, Delft University of Technology).

de Vriend, H. N. (1987). 2DH mathematical modelling of morphological evolutions in shallow water. Coastal Engineering, 11(1), 1-27.

Wengrove, M. E., Foster, D. L., de Schipper, M. A., \& Lippmann, T. C. (2017). Wave and current ripple formation and migration during storms. In Proceedings of Coastal Dynamics (Vol. 129). 